\title{
BMJ Open Opioid substitution therapy as a strategy to reduce deaths in prison: retrospective cohort study
}

\author{
Sarah Larney, ${ }^{1,2}$ Natasa Gisev,${ }^{1}$ Michael Farrell, ${ }^{1}$ Timothy Dobbins, ${ }^{3}$ \\ Lucinda Burns, ${ }^{1}$ Amy Gibson, ${ }^{4}$ Jo Kimber, ${ }^{1}$ Louisa Degenhardt ${ }^{1,5}$
}

To cite: Larney S, Gisev N, Farrell M, et al. Opioid substitution therapy as a strategy to reduce deaths in prison: retrospective cohort study. BMJ Open 2014;4: e004666. doi:10.1136/ bmjopen-2013-004666

- Prepublication history and additional material is available. To view please visit the journal (http://dx.doi.org/ 10.1136/bmjopen-2013004666).

Received 11 December 2013 Revised 5 March 2014 Accepted 7 March 2014

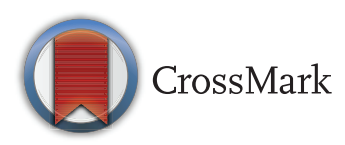

${ }^{1}$ National Drug and Alcohol Research Centre, University of New South Wales, Sydney, Australia

${ }^{2}$ Alpert Medical School, Brown University, Providence, USA

${ }^{3}$ School of Public Health, University of Sydney, Sydney, Australia

${ }^{4}$ Centre for Health Research, University of Western Sydney, Sydney, Australia

${ }^{5}$ Centre for Health Policy, Programs and Economics, University of Melbourne, Melbourne, Australia

Correspondence to Dr Sarah Larney; s.larney@unsw.edu.au

\section{ABSTRACT}

Objectives: To describe deaths in prison among opioid-dependent people, and examine associations between receipt of opioid substitution therapy (OST) and risk of death in prison.

Design: Retrospective cohort study.

Setting: Adult prisons in New South Wales (NSW), Australia.

Participants: 16715 opioid-dependent people who were received to prison between 2000 and 2012.

Interventions: Opioid substitution therapy.

Primary outcome measures: Natural and unnatural (suicide, drug-induced, violent and other injury) deaths in prison.

Results: Cohort members were in prison for 30998 person-years (PY), during which time there were 51 deaths. The all-cause crude mortality rate (CMR) in prison was $1.6 / 1000 \mathrm{PY}(95 \% \mathrm{Cl} 1.2$ to $2.2 / 1000 \mathrm{PY})$, and the unnatural death CMR was 1.1/1000 PY (95\% $\mathrm{Cl} 0.8$ to $1.6 / 1000 \mathrm{PY}$ ). Compared to time out of OST, the hazard of all-cause death was $74 \%$ lower while in OST (adjusted HR (AHR): 0.26 ; $95 \% \mathrm{Cl} 0.13$ to 0.50 ), and the hazard of unnatural death was $87 \%$ lower while in OST (AHR: $0.13 ; 95 \% \mathrm{CI} 0.05$ to 0.35 ). The all-cause and unnatural death CMRs during the first 4 weeks of incarceration were $6.6 / 1000 \mathrm{PY}(95 \% \mathrm{Cl}$ 3.8 to $10.6 / 1000 \mathrm{PY})$ and 5.5/1000 PY (95\% Cl 2.9 to $9.4 / 1000 \mathrm{PY}$ ), respectively. Compared to periods not in OST, the hazard of all-cause death during the first 4 weeks of incarceration was $94 \%$ lower while in OST (AHR: $0.06 ; 95 \% \mathrm{Cl} 0.01$ to 0.48 ), and the hazard of unnatural death was $93 \%$ lower while in OST (AHR: $0.07 ; 95 \% \mathrm{Cl} 0.01$ to 0.53 ).

Conclusions: Mortality of opioid-dependent prisoners was significantly lower while in receipt of OST.

\section{INTRODUCTION}

Deaths in prison are a serious public health issue, raising questions as to the quality of care and supervision provided by correctional authorities. Reflecting such concerns, deaths in prison usually result in extensive postmortem inquiries and may also lead to litigation against correctional authorities and healthcare providers. ${ }^{1}$

\section{Strengths and limitations of this study}

- This study is based on a large, statewide cohort with mortality outcomes determined via population-based registries.

- Cohort members were not randomly allocated to treatment.

- Data regarding onset of opioid dependence and current opioid dependence were not available.

Unnatural deaths in prison are of particular concern due to their preventable nature. Unnatural deaths include suicides, violent or drug-induced deaths and other injury-related deaths. Studies in developed countries have found that unnatural deaths comprise 48$59 \%$ of all deaths in prison, with suicide being the most common cause of unnatural death. ${ }^{2-5}$ These figures suggest considerable opportunities to reduce unnatural deaths in prison.

Opioid-dependent people commonly experience imprisonment, ${ }^{6}$ and there are several reasons to believe that opioiddependent prisoners may be at particular risk of unnatural death in prison. Drug withdrawal has been implicated as a possible trigger for suicide in the first days of incarceration. $^{7}{ }^{8}$ Additionally, use of illicitly obtained opioids while in prison $^{9}$ carries with it the risk of overdose. To the best of our knowledge, deaths in prison specifically among opioid-dependent people have not been described previously. Furthermore, no studies have considered whether treatment for opioid dependence during incarceration reduces mortality risk, as it does among opioid-dependent people residing in the community. ${ }^{10}$ In this study, we describe deaths in prison in a cohort of opioiddependent people and examine whether receiving opioid substitution therapy (OST) reduces the risk of death in prison. 


\section{METHODS}

\section{Setting}

New South Wales (NSW) is the most populous state in Australia and houses around one-third of the country's prisoners, or 9645 people at 31 June $2012 .{ }^{11}$ Health services in NSW prisons are provided under the Ministry of Health, and there is a well-established prison OST programme that operates as part of the statewide opioid treatment programme. ${ }^{12}{ }^{13}$ People who enter prison while in OST may continue treatment while incarcerated, and OST can be started during incarceration if clinically indicated. ${ }^{12}$ Clinical indications for OST are the same as in community settings. ${ }^{13}$ Most prisoners receiving OST are prescribed methadone due to the longer dosing procedure associated with buprenorphine and concerns about diversion of buprenorphine. In 2012, 16\% of NSW prisoners were prescribed OST. ${ }^{11}{ }^{12}$ Coverage of OST (the proportion of opioid-dependent prisoners receiving treatment) has been estimated at $43 \% .{ }^{14}$

\section{Data sources and linkage}

Data for this retrospective cohort study were extracted from administrative datasets used to record OST programmes, offending and incarceration, and mortality. The Pharmaceutical Drugs of Addiction System (PHDAS) is a database of all methadone and buprenorphine recipients in NSW since 1985. The PHDAS records each patient's full name, date of birth, gender and clinical variables including dates of OST entry and exit. Identifying variables in this dataset are considered to be of high accuracy as proof of identity must be shown to the prescribing doctor before a prescription can be issued. Data used for linkage were for the calendar years 1985-2010.

Offending and incarceration data were sourced from the NSW Bureau of Crime Statistics and Research (BOCSAR) Re-offending Database (ROD). This database includes dates and types of offences in criminal cases heard by local, district and supreme courts of NSW, and dates of receptions to and discharges from the custody of Corrective Services NSW. All available data were provided for linkage; this included offending data for the period 1 December 1993 to 31 December 2011 and incarceration data for the period 1 January 2000 to 31 March 2012.

The National Death Index (NDI) is a database held by the Australian Institute of Health and Welfare (AIHW), containing mortality data collected from all the Registry of Births, Deaths and Marriages in each Australian State and Territory. Causes of death are recorded in the NDI by expert clinical coders on the basis of information contained in death certificates and, where available, coronial files, using the International Statistical Classification of Diseases and Related Health Problems 10th Edition (ICD-10). Dates of death were available for the entire period for which incarceration data were available (1 January 2000 to 31 March 2012); however, for administrative reasons, causes of death were available only for deaths occurring up to 31 December 2010.

Linkage between the OST and offending/incarceration data was performed by BOCSAR staff, and linkage between the OST and mortality data was undertaken by AIHW staff. Linkage was completed using probabilistic linkage software. Variables used for matching purposes included full name, date of birth, gender, and date and state of last known contact where available. These linked datasets were forwarded to the investigators with identifiers removed.

\section{Cohort and data definitions}

From the linked datasets, we identified a cohort of opioid-dependent people (people who were recorded in the PHDAS as having received OST at some point during 1986-2010) who had been incarcerated at least once (as recorded in the ROD). In defining receipt of OST, we excluded temporary treatment programmes (usually interstate visitors) and treatment episodes that were part of a buprenorphine clinical trial (during which the individual may have been allocated to placebo). Periods in the custody of Corrective Services NSW were determined using reception and discharge dates in the ROD. We used the first recorded OST episode as a proxy for the onset of opioid dependence and excluded prison episodes that occurred prior to the first OST episode; all subsequent prison episodes for an individual were included. If an individual's first OST episode started while incarcerated, that prison episode was included. Given the chronic and relapsing nature of opioid dependence, ${ }^{15}{ }^{16}$ we assumed that all cohort members remained opioid-dependent from their first episode of OST until death or the end of follow-up.

Deaths in prison were defined as deaths that occurred while the individual was recorded as being in the custody of Corrective Services NSW. This definition does not stipulate that a deceased individual was physically in prison at the time of death. Some decedents may have been receiving care in hospital at the time of death, while still in the custody of Corrective Services NSW. Deaths with known causes (ie, all deaths occurring in the calendar years 2000-2010) were categorised as natural (ie, disease-related) or unnatural deaths. We used the Corrective Services NSW definition of 'unnatural deaths', which includes suicides, drug-induced deaths, violent deaths and deaths due to accidental injuries or injuries in which no intent (ie, suicidal or violent) could be determined. ${ }^{3}$ ICD-10 codes for unnatural deaths are provided in the online supplementary materials.

Periods of OST while in prison, and treatment status (in OST/out of OST) at the time of death, were determined using treatment entry and exit dates from the PHDAS. New treatment episodes were defined when an individual started treatment 7 or more days after discharge from a previous treatment episode. A change in medicine (methadone to buprenorphine, or vice versa) 
was considered a continuous episode if there were less than 7 days between ceasing one medicine and startingthe other.

\section{Data analysis}

Statistical analyses were undertaken in SAS V.9.3. We used descriptive statistics to examine demographic characteristics and incarceration. Participants with any record of receiving OST in prison were compared with those who did not receive OST in prison using $\chi^{2}$ tests for categorical variables and the Wilcoxon rank-sum test for continuous variables. We constructed a frequency histogram to illustrate time from entry to prison until death. For dates for which comparable data were available (financial years 2000-2001 to 2009-2010), we compared the total number of unnatural deaths among prisoners in $\mathrm{NSW}^{3}$ with the number of unnatural deaths in the opioid-dependent cohort.

We calculated all-cause and cause-specific crude mortality rates (CMR) with Poisson 95\% CI for all time in prison and for the first 4 weeks in prison. Rates were also calculated by treatment status (in/out of OST). Person-years (PY) used in the calculation of CMRs accrued whenever participants were in the custody of Corrective Services NSW. Prison episodes where the participant was received and released on the same day were counted as 1 day. PY ceased to accrue at death on 31 March 2012 for all-cause mortality rates, and on 31 December 2010 for cause-specific mortality rates. CMR ratios with 95\% CI were calculated to assess unadjusted risk of death in treatment compared with that out of treatment. The rate ratio (RR) was not calculated if there were zero deaths in either the in-treatment or out-of-treatment condition.

We used Cox regression to examine the adjusted association between OST exposure and two in-prison mortality outcomes: deaths from all causes and unnatural deaths. Two models were developed for each outcome: the first considering mortality risk across all time in prison, and the second examining mortality risk during the first 4 weeks of incarceration. All prison episodes were included, with days in prison counted as discontinuous intervals at risk. Although participants could have multiple observations within the dataset, the internal computations of a Cox model are such that when there is only one event of interest per person (in this case, death), there is no need for adjustments for multiple observations. ${ }^{17}$ OST exposure while in prison was coded as a time-dependent variable, with periods out of treatment coded as 0 and periods in treatment coded as 1. Demographic variables included in the models were gender, indigenous (ie, Aboriginal or Torres Strait Islander) status and age at entry to prison; this latter variable increased as necessary with subsequent incarcerations of an individual. We also included variables that described prior experiences of incarceration during our observation periods, namely, the number and duration (days) of prior incarcerations.
These variables increased with each incarceration per person. We also included dichotomous variables that recorded if a participant had been charged with a drug, property or violent offence prior to incarceration. These were included because of possible associations between death in prison (particularly suicide) and prior offending (particularly violent offending). ${ }^{18} 19$ The offending history variables could change from no to yes with subsequent incarcerations. Observations with missing covariate data were excluded from the analyses. We tested each variable for its bivariate association with mortality and entered all variables into a multivariate model. We tested the proportional hazards assumption for each static predictor variable in the multivariate model by including an interaction between it and log (time) in the model. All variables in both models were found to satisfy the proportional hazards assumption.

\section{RESULTS}

The cohort comprised 16715 opioid-dependent people who had been incarcerated at least once between January 2000 and March 2012 (table 1). The majority $(79 \% ; \mathrm{n}=13199)$ of the cohort was male, and $30 \%$ $(\mathrm{n}=5011)$ were identified as indigenous. The median age at first entry to prison during our observation period was 30 years (ranging from 16 to 64 years).

Cohort members were received in prison a median of two times (ranging between 1 and 34). Duration of incarceration ranged from 1 day to the entire length of follow-up (12 years and 3 months), with a median duration of 71 days. Most participants $(76.9 \%$; $n=12852)$ received OST at some point while incarcerated. Compared to participants who received OST in prison, participants who did not receive OST in prison were significantly older, less likely to be indigenous and have fewer incarcerations of shorter duration (table 1).

\section{Deaths in prison}

Fifty-one cohort members died in prison (table 2). Most were men $(90 \% ; \mathrm{n}=46)$ and non-indigenous $(73 \%$; $\mathrm{n}=37$ ). The median age at death was 34 years (ranging between 20 and 54). Only 22\% ( $\mathrm{n}=11)$ of decedents were receiving OST at the time of death. Cause of death was available for 43 deaths in prison. Of these, nearly three-quarters (74\%; $\mathrm{n}=32)$ were unnatural deaths: 19 suicides, 6 drug-related deaths, 2 violent deaths and 5 deaths due to other injuries. Between the financial years 2000-2001 and 2009-2010, unnatural deaths in this cohort accounted for $35 \%$ of all unnatural deaths in NSW prisons ${ }^{3}$ (see online supplementary materials for further details).

One-third of all deaths in prison $(n=17)$ occurred during the first 4 weeks of incarceration (figure 1). Of these, three-quarters $(13 / 17 ; 76 \%)$ were unnatural deaths: 10 suicides, 2 other injury-related deaths and 1 drug-related death. 
Table 1 Demographic characteristics of opioid-dependent persons received to prison, New South Wales, Australia, 2000-2012 (n=16 715)

\begin{tabular}{|c|c|c|c|c|}
\hline Characteristic & $\begin{array}{l}\text { Total } \\
(n=16715)\end{array}$ & $\begin{array}{l}\text { Ever received OST in } \\
\text { prison }(n=12852)\end{array}$ & $\begin{array}{l}\text { No OST in prison } \\
(n=3863)\end{array}$ & p Value \\
\hline Male, n (\%) & $13199(79)$ & $10109(78.7)$ & $3090(80)$ & 0.07 \\
\hline $\begin{array}{l}\text { Age (years) at first observed entry to prison, } \\
\text { median (minimum-maximum) }\end{array}$ & $30(16-64)$ & $29(16-63)$ & $32(17-64)$ & $<0.0001$ \\
\hline Indigenous, ${ }^{*} \mathrm{n}(\%)$ & $5011(30)$ & $4208(32.8)$ & $803(20.8)$ & $<0.0001$ \\
\hline $\begin{array}{l}\text { Number of prison episodes, median } \\
\text { (minimum-maximum) }\end{array}$ & $2(1-34)$ & $3(1-34)$ & $1(1-23)$ & $<.0001$ \\
\hline $\begin{array}{l}\text { Duration (days) of prison episodes, median } \\
\text { (minimum-maximum) }\end{array}$ & $71(1-4473)$ & $77(1-4473)$ & $46(1-4473)$ & $<0.0001$ \\
\hline Any receipt of OST in prison & $12852(76.9)$ & - & - & - \\
\hline
\end{tabular}

\section{Crude mortality rates}

The all-cause CMR in prison was $1.6 / 1000$ PY (95\% CI 1.2 to $2.2 / 1000 \mathrm{PY}$ ) (table 3 ). The all-cause CMR was significantly lower while in OST (CMR: 0.7/1000 PY; 95\% CI 0.3 to $1.2 / 1000 \mathrm{PY}$ ), compared to time out of OST (CMR: 2.7/1000 PY; 95\% CI 2.0 to $3.7 / 1000$ PY) (RR: $0.24 ; 95 \%$ CI 0.12 to 0.47 ).

Deaths from natural causes occurred at similar rates whether in $(0.3 / 1000 \mathrm{PY} ; 95 \%$ CI 0.1 to $0.8 / 1000 \mathrm{PY})$ or out $(0.5 / 1000 \mathrm{PY} ; 95 \% \mathrm{CI} 0.2$ to $1 / 1000 \mathrm{PY})$ of OST (RR: $0.68 ; 95 \%$ CI 0.21 to 2.21 ). There was, however, a marked effect of OST on rates of unnatural death. The in-treatment CMR for unnatural deaths was 0.3/1000 PY (95\% CI 0.1 to $0.8 / 1000 \mathrm{PY}$ ), compared to $2.2 / 1000 \mathrm{PY}$ (95\% CI 1.4 to $3.2 / 1000 \mathrm{PY}$ ) while out of OST (RR: $0.15 ; 95 \%$ CI 0.06 to 0.39$)$. Of the specific unnatural causes of death, suicides were significantly less frequent while in OST (CMR: 0.2/1000 PY; 95\% CI 0.04 to $0.6 /$ 1000 PY) than while not in OST (CMR: 0.2/1000 PY;

Table 2 Demographic characteristics and causes of death of opioid-dependent persons who died in prison, New South Wales, Australia, 2000-2012 $(n=51)$

\begin{tabular}{lc}
\hline Characteristic & $\mathbf{N}(\%)$ \\
\hline Male & $46(90)$ \\
Age (years) at death, median & $34(20-54)$ \\
(minimum-maximum) & \\
Indigenous & $14(27)$ \\
In OST at time of death & $11(22)$ \\
Deaths from natural causes* & $11(26)$ \\
Unnatural deaths* & $32(74)$ \\
Suicide & $19(44)$ \\
Drug-related & $6(14)$ \\
Violent & $2(5)$ \\
Other injury-related & $5(12)$ \\
\hline${ }^{*}$ Cause of death unknown for eight decedents. Percentage is \\
based on $n=43$.
\end{tabular}

95\% CI 0.04 to $0.6 / 1000$ PY) (RR: 0.15 ; $95 \%$ CI 0.04 to 0.52). Of the six observed drug-induced deaths and five other injury deaths, none occurred during OST, but both violent deaths occurred while in OST.

During the first 4 weeks of incarceration, the all-cause CMR was 6.6/1000 PY (95\% CI 3.8 to $10.6 / 1000$ PY). Of the 17 cohort members who died during the first 4 weeks of incarceration, only one was receiving OST at the time of death. The in-treatment all-cause CMR in the first 4 weeks of incarceration was 0.8 deaths/1000 PY (95\% CI 0.02 to $4.3 / 1000 \mathrm{PY})$, significantly lower than the CMR of $12.7 / 1000$ PY (95\% CI 7.2 to $20.6 / 1000$ PY) observed among out-of-treatment cohort members (RR: 0.06; $95 \%$ CI 0.01 to 0.45$)$. Across all time in prison, the natural mortality rate did not differ by OST status, but the in-treatment CMR for unnatural deaths (0.8/1000 PY; $95 \%$ CI 0.02 to $4.4 / 1000 \mathrm{PY}$ ) was significantly lower than the out-of-treatment CMR for unnatural deaths (11/1000 PY; 95\% CI 5.7 to $19.2 / 1000$ PY) (RR: 0.07;

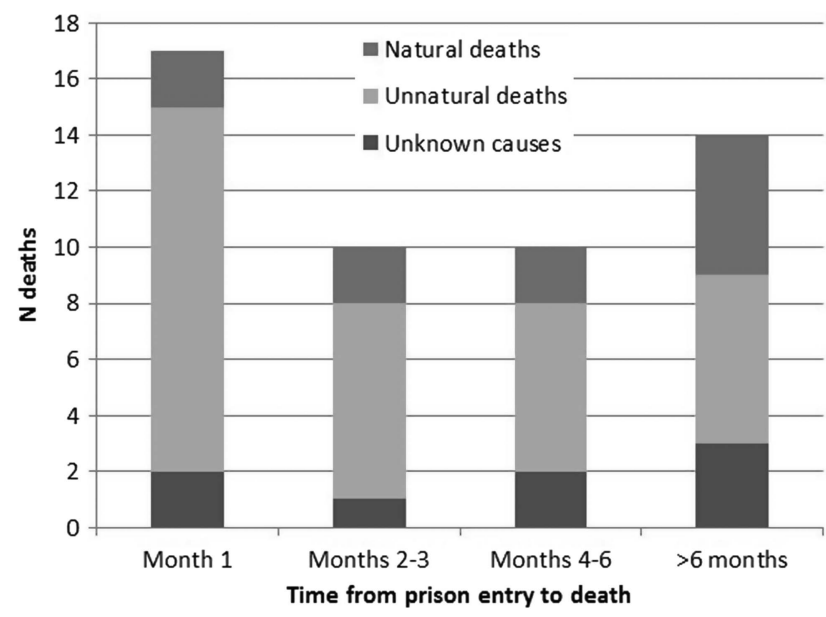

Figure 1 Deaths from natural, unnatural and unknown causes, by time in prison prior to death among opioid-dependent people who died in prison, New South Wales, Australia, 2000-2012 ( $n=51)$. 
Table 3 All-cause and cause-specific crude mortality rates per 1000 person-years in prison among opioid-dependent people in New South Wales, Australia, 2000-2012 ( $n=16715)$

\begin{tabular}{|c|c|c|c|c|c|c|c|c|}
\hline \multirow[b]{2}{*}{ Cause of death } & \multicolumn{4}{|c|}{ Total time in prison } & \multicolumn{4}{|c|}{ First 4 weeks in prison } \\
\hline & PY & Deaths & $\begin{array}{l}\text { Crude mortality } \\
\text { rate }(95 \% \mathrm{Cl})\end{array}$ & $\begin{array}{l}\text { Rate ratio } \\
(95 \% \mathrm{Cl})\end{array}$ & PY & Deaths & $\begin{array}{l}\text { Crude mortality } \\
\text { rate }(95 \% \mathrm{Cl})\end{array}$ & $\begin{array}{l}\text { Rate ratio } \\
(95 \% \mathrm{Cl})\end{array}$ \\
\hline All cause & 30988 & 51 & 1.6 (1.2 to 2.2$)$ & & 2571 & 17 & 6.6 (3.8 to 10.6$)$ & \\
\hline Out of OST & 14548 & 40 & 2.7 (2 to 3.7$)$ & & 1263 & 16 & 12.7 (7.2 to 20.6$)$ & \\
\hline In OST & 16440 & 11 & 0.7 (0.3 to 1.2$)$ & $0.24(0.12$ to 0.47$)$ & 1308 & 1 & $0.8(0.02$ to 4.3$)$ & 0.06 (0.01 to 0.45$)$ \\
\hline $\begin{array}{l}\text { Unnatural } \\
\text { causes }^{*}\end{array}$ & 27839 & 32 & $1.1(0.8$ to 1.6$)$ & & 2374 & 13 & 5.5 (2.9 to 9.4$)$ & \\
\hline Out of OST & 12462 & 27 & 2.2 (1.4 to 3.2 ) & & 1094 & 12 & 11.0 (5.7 to 19.2$)$ & \\
\hline In OST & 15377 & 5 & 0.3 (0.1 to 0.8$)$ & 0.15 (0.06 to 0.39$)$ & 1279 & 1 & $0.8(0.02$ to 4.4$)$ & 0.07 (0.01 to 0.55$)$ \\
\hline Suicide & 27839 & 19 & $0.7(0.4$ to 1.1$)$ & & 2374 & 10 & $4.2(2$ to 7.7$)$ & \\
\hline Out of OST & 12462 & 16 & $1.3(0.7$ to 2.1$)$ & & 1094 & 9 & 8.2 (3.8 to 15.6$)$ & \\
\hline In OST & 15377 & 3 & $0.2(0.04$ to 0.6$)$ & 0.15 (0.04 to 0.52$)$ & 1279 & 1 & $0.8(0.02$ to 4.4$)$ & $0.10(0.01$ to 0.75$)$ \\
\hline Drug-induced & 27839 & 6 & $0.2(0.08$ to 0.5$)$ & & 2374 & 1 & 0.4 (0.01 to 2.3 ) & - \\
\hline Out of OST & 12462 & 6 & $0.5(0.2$ to 1$)$ & & 1094 & 1 & $1.0(0.02$ to 5.1$)$ & \\
\hline In OST & 15377 & 0 & - & - & 1279 & 0 & - & \\
\hline Violence & 27839 & 2 & $0.07(0.01$ to 0.3$)$ & & 2374 & 0 & - & - \\
\hline Out of OST & 12462 & 0 & - & & 1094 & 0 & - & \\
\hline In OST & 15377 & 2 & $0.1(0.02$ to 0.5$)$ & - & 1279 & 0 & - & \\
\hline Other injuries & 27839 & 5 & $0.2(0.06$ to 0.4$)$ & & 2374 & 2 & $0.8(0.1$ to 3$)$ & - \\
\hline Out of OST & 12462 & 5 & $0.4(0.1$ to 0.9$)$ & & 1094 & 2 & $1.8(0.2$ to 6.6$)$ & \\
\hline In OST & 15377 & 0 & - & - & 1279 & 0 & - & \\
\hline Natural causes & 27839 & 11 & $0.4(0.2$ to 0.7$)$ & & 2374 & 2 & 0.8 (0.1 to 3$)$ & - \\
\hline Out of OST & 12462 & 6 & $0.5(0.2$ to 1.0$)$ & & 1094 & 2 & $1.8(0.2$ to 6.6$)$ & \\
\hline In OST & 15377 & 5 & 0.3 (0.1 to 0.8$)$ & 0.68 (0.21 to 2.21$)$ & 1279 & 0 & - & \\
\hline
\end{tabular}

Cause of death missing for eight deaths.

*Includes suicide, drug-induced, violent and other injury deaths.

OST, opioid substitution treatment; PY, person-years.

95\% CI 0.01 to 0.55$)$. The same pattern was observed in relation to suicide deaths (in-OST CMR: 0.8/1000 PY, 95\% CI 0.02 to 4.4/1000 PY; out-of-OST CMR: 8.2/1000 PY, 95\% CI 3.8 to $15.6 / 1000$ PY; RR: $0.10,95 \%$ CI 0.01 to $0.75)$.

\section{Adjusted effect of OST on deaths in custody}

In the first 4 weeks of a prison episode, the all-cause mortality hazard was $94 \%$ lower while in OST, compared to being out of OST (adjusted HR (AHR): 0.06; 95\% CI 0.01 to 0.48$)$, regardless of gender, indigenous status, age, incarceration history or offending history (table 4). A similar finding was observed in relation to unnatural deaths; during the first 4 weeks of a prison episode, while in OST, the hazard of unnatural death was 93\% lower than while not in OST (AHR 0.07; 95\% CI 0.01 to 0.59 ).

Across all time in prison, the all-cause mortality hazard during periods of OST was reduced by threequarters compared with periods not in OST (AHR: 0.26; $95 \%$ CI 0.13 to 0.50$)$, regardless of gender, indigenous status, age, incarceration history or offending history. Across all time in prison, compared with periods not in OST, the hazard of unnatural death was $87 \%$ lower while in OST (AHR: 0.13; 95\% CI 0.05 to 0.35 ).

\section{DISCUSSION}

We have demonstrated a very strong association between receipt of OST and lowered mortality among opioid- dependent prisoners. After adjusting for demographic and criminal history factors, compared to time not in OST, being in OST was associated with a $74 \%$ lower hazard of dying in prison. The association between mortality risk and OST was driven by the reduction in unnatural deaths, with periods in OST associated with an $87 \%$ decrease in mortality hazard compared to time not in OST. One-third of deaths in prison in this cohort occurred during the first 4 weeks of incarceration; in these initial weeks in prison, compared to time not in OST, being in OST was associated with a $94 \%$ lower allcause mortality hazard and a 93\% lower hazard of unnatural death. Although the CIs around the HRs were wide, even the uppermost limits of the intervals suggested substantial reductions in mortality while in OST. For example, across all time in prison, there was at least a $65 \%$ reduction in unnatural mortality hazard while in OST compared to time not in OST.

The cohort included in this study was drawn from a large, statewide administrative dataset of people receiving treatment for opioid dependence. Although precise data are not available on the representativeness of this cohort, in sentinel surveillance studies of people who inject drugs in NSW (98\% of whom have a history of illicit opioid use), almost $60 \%$ of participants are currently in OST, and more than $80 \%$ have a history of $\mathrm{OST}^{20}$ suggesting that the cohort is highly representative of the NSW opioid-dependent population. The subset of this population that had been incarcerated was included 


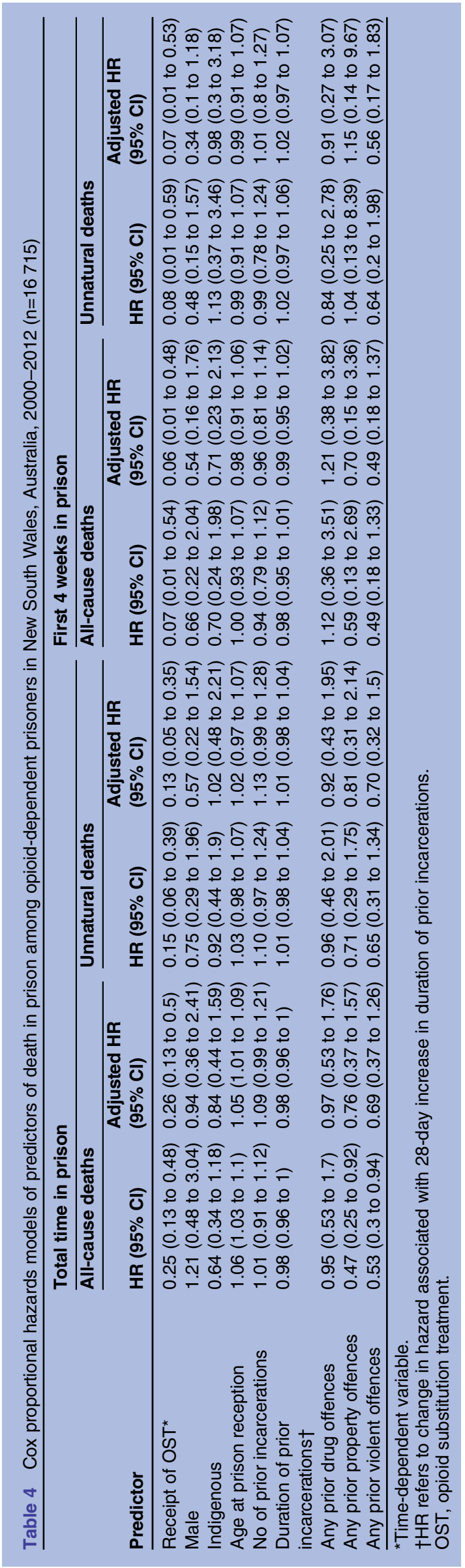

in this study. As an observational study, cohort members were not randomly allocated to treatment. Although there were some differences between prisoners who did and did not receive OST, these variables did not affect the association between OST and mortality. We did not have clinical indicators of current opioid dependence, and it is possible that some members of our cohort may have ceased all opioid use, thereby reducing their baseline mortality risk. However, given the chronic and relapsing nature of opioid dependence, ${ }^{15}{ }^{16}$ this is unlikely to have been the case for any substantial proportion of the cohort. Inclusion of opioid-abstinent individuals would, at any rate, result in conservative mortality estimates. Finally, we used the first episode of OST as a proxy for the onset of opioid dependence. It is possible that some cohort members had previous incarcerations during which they were opioid dependent, but had not yet entered OST.

To the best of our knowledge, this is the first study of its kind. Prior studies have reported on all-cause or cause-specific mortality in prison among total prisoner populations. ${ }^{4122}$ We have extended on these studies by analysing mortality in opioid-dependent prisoners-a group with known mortality risk factors. Compared with opioid-dependent populations at liberty, mortality rates were low in opioid-dependent prisoners. ${ }^{10}$ This is most likely a result of limited access to illicit opioids and low exposure to other common causes of death in this population, such as motor vehicle accidents. ${ }^{23}$ Highlighting the vulnerability of this population, however, $74 \%$ of deaths in prison were due to unnatural causes, compared to $48-59 \%$ of deaths in studies of total prisoner populations..$^{2-5}$ The great majority of deaths occurred while prisoners were not receiving OST. Although this protective effect of OST against mortality is known, ${ }^{10}$ this is the first time that this association has been observed in a prison setting. Prior studies of OST in correctional settings, including a clinical trial ${ }^{24}$ and prospective cohort studies, ${ }^{25}{ }^{26}$ have not reported any deaths during OST, but these were not powered to detect differences in mortality rates during periods in and out of treatment. Receipt of OST in prison also reduces illicit opioid use and injecting drug use, ${ }^{24} 27$ and is associated with reduced institutional drug charges. ${ }^{28}$ Opioid-dependent prisoners who receive OST are more likely than their untreated peers to enrol in OST following release, ${ }^{29}$ and continuation of OST on release is associated with reduced reincarceration ${ }^{30}$ and reduced postrelease mortality. ${ }^{31}$

Although we have demonstrated a very strong protective effect of OST against death in prison for opioiddependent prisoners, several questions remain to be answered. This study was undertaken in a jurisdiction with relatively high OST coverage. ${ }^{14}$ Our understanding of the relationship between OST and deaths in prison could benefit from further observational or simulation studies that assess the impact of varying levels of OST coverage on deaths. Further, this study was not able to 
determine why it is that OST should be associated with reduced unnatural deaths. Given that drug withdrawal symptoms have been implicated as a trigger for suicide in the first week of prison, ${ }^{78}$ the association may, in part at least, be due to alleviation or prevention of opioid withdrawal. If it is the case that averting withdrawal symptoms is sufficient to prevent some prison suicides, there are important implications for the clinical management of withdrawal symptoms of prisoners dependent on nonopioid drugs. Research examining why there are fewer suicides among opioid-dependent prisoners in OST is needed, as is research examining whether management of withdrawal from non-opioid drugs has a similar impact on suicides in prison.

The implication of these findings for correctional authorities and prison medical providers is clear; ensuring a high coverage of OST in correctional settings will help to minimise unnatural deaths among opioiddependent prisoners. Given the particularly high mortality risk observed during the first 4 weeks of incarceration, it is critical that opioid-dependent prisoners can access OST in a timely manner. Opioid dependence and enrolment in OST immediately prior to entry to prison should be assessed during intake medical examinations. Prisoners enrolled in OST prior to prison entry should be able to continue this treatment without interruption, and other opioid-dependent prisoners should be assessed for OST and offered treatment if clinically indicated. Although there are challenges to the implementation of OST programmes in prisons and other correctional settings, these can be managed through strong executive leadership, ongoing training and education for health and custodial staff, and careful attention to issues of safety and security. ${ }^{32}$

Acknowledgements The authors wish to acknowledge all data custodians for providing access to the datasets used in this study: the NSW Ministry of Health (PHDAS dataset), the Bureau of Crime Statistics and Research (ROD dataset) and the Australian Institute of Health and Welfare (NDI dataset). They thank Judy Trevena for her work on the initial preparation and cleaning of datasets, Pia Salmelainen (NSW Health) for expert advice about the PHDAS dataset and Jacqui Fitzgerald (BOCSAR) for advice regarding the ROD. They also wish to thank the members of our Indigenous Reference Group: Michael Doyle, Anton Clifford, Megan Williams and Luke Bell.

Contributors SL completed the analysis and led the writing and is responsible for the overall content as guarantor. TD provided statistical advice and contributed to the writing. NG, MF, LB, AG and JK contributed to the writing. LD oversaw the larger project for which these data were obtained and contributed to the writing.

Funding Funding for the work undertaken for this manuscript was provided by a project grant from the National Health and Medical Research Council (NHMRC) (grant no. 1005668). This project was also supported by a grant from the Australian Institute of Criminology (AIC) through the Criminology Research Grants Program. SL and LD are supported by NHMRC Research Fellowships (numbers 1035149 and 1041742, respectively). LD has received untied educational grants from Reckitt Benckiser to conductpostmarketing surveillance of the diversion and injection of opioids. MF has participated in workshops in the Asia-Pacific region on the development of treatment services and on research with opioid users; these were supported by Reckitt Benckiser through an unrestricted educational grant, paid to the University of Adelaide.

Competing interests None.
Ethics approval Research ethics committees of the University of New South Wales (NSW) (HC12019), the NSW Ministry of Health (2011/11/360), the Australian Institute of Health and Welfare (EC2011/2/13), the Alfred Hospital (165/11), Corrective Services NSW (11/82607), Justice Health (NSW) (G219/11), the NSW Aboriginal Health and Medical Research Council (AHMRC) (793/11) and Justice Health (Victoria) (CF/13/3440C).

Provenance and peer review Not commissioned; externally peer reviewed.

Data sharing statement No additional data are available.

Open Access This is an Open Access article distributed in accordance with the Creative Commons Attribution Non Commercial (CC BY-NC 3.0) license, which permits others to distribute, remix, adapt, build upon this work noncommercially, and license their derivative works on different terms, provided the original work is properly cited and the use is non-commercial. See: http:// creativecommons.org/licenses/by-nc/3.0/

\section{REFERENCES}

1. Paris JE. Three cases of correctional litigation: learning from the root causes. J Correct Health Care 2010;16:39-47.

2. Brittain J, Axelrod G, Venters H. Deaths in New York City jails. Am J Public Health 2013;103:638-40.

3. Corrective Services NSW. Statistical report 2011/12. Sydney Corrective Services NSW, 2012.

4. Fazel S, Benning R. Natural deaths in male prisoners: a 20-year mortality study. Eur J Public Health 2006;16:441-4.

5. Woebeser WL, Datema J, Bechard B, et al. Causes of death among people in custody in Ontario, 1990-1999. C M A J 2002;167: 1109-13.

6. Degenhardt L, Larney S, Trevena J, et al. Imprisonment of opioid dependent people in New South Wales, Australia, 2000-2012: retrospective linkage study. Aust N Z J Public Health 2013; in press. doi:10.1111/1753-6405.12123

7. Rivlin A, Ferris R, Marzano L, et al. A typology of male prisoners making near-lethal suicide attempts. Crisis 2013;34:335-47.

8. Humber N, Piper M, Appleby L, et al. Characteristics of and trends in subgroups of prisoner suicides in England and Wales. Psychol Med 2011:41:2275-85

9. Strang J, Gossop M, Heuston J, et al. Persistence of drug use during imprisonment: relationship of drug type, recency of use and severity of dependence to use of heroin, cocaine and amphetamine in prison. Addiction 2006;101:1125-32.

10. Degenhardt L, Bucello C, Mathers BM, et al. Mortality among regula or dependent users of heroin and other opioids: a systematic review and meta-analysis of cohort studies. Addiction 2011;106:32-51.

11. Australian Bureau of Statistics. Prisoners in Australia, 2012 Canberra: Australian Bureau of Statistics, 2012

12. Justice Health and Forensic Mental Health Network. Year in review 2011/12. Sydney: Justice Health and Forensic Mental Health Network, 2012.

13. NSW Health Department. Opioid treatment program: clinical guidelines for methadone and buprenorphine treatment. Sydney: NSW Health Department, 2006.

14. Larney S, Indig D. Trends in illicit drug use in Australian correctional centres [abstract]. Annual meeting of the college of problems on drug dependence. California: Palm Springs, 2012.

15. Hser Y, Hoffman V, Grella CE, et al. A 33-year follow-up of narcotics addicts. Arch Gen Psychiatry 2001;58:503-8.

16. Nosyk B, Anglin MD, Brecht M, et al. Characterizing durations of heroin abstinence in the California Civil Addict Program: results from a 33-year observational cohort study. Am J Epidemiol 2013;177:675-82.

17. Therneau TM, Grambsch PM. Modeling survival data: extending the Cox model. New York: Springer-Verlag, 2000.

18. Way BB, Miraglia R, Sawyer DA, et al. Factors related to suicide in New York state prisons. Int J Law Psychiatry 2005;28:207-21.

19. Humber N, Webb R, Piper M, et al. A national case-control study of risk factors among prisoners in England and Wales. Soc Psychiatry Psychiatr Epidemiol 2013;48:1177-85.

20. Van Buskirk J, Burns L. NSW drug trends 2012: findings from the Illicit Drug Reporting System (IDRS). Sydney: National Drug and Alcohol Research Centre, University of New South Wales, 2013.

21. Rosen DL, Wohl DA, Schoenbach VJ. All-cause and cause-specific mortality among Black and White North Carolina state prisoners, 1995-2005. Ann Epidemiol 2011;21:719-26.

22. Harzke AJ, Baillargeon JG, Kelley MF, et al. Leading medical causes of mortality among male prisoners in Texas, 1992-2003. J Correct Health Care 2011;17:241-53. 
23. Spaulding AC, Seals RM, McCallum VA, et al. Prisoner survival inside and outside of the institution: implications for health-care planning. Am J Epidemiol 2011;173:479-87.

24. Dolan $\mathrm{K}$, Shearer $\mathrm{J}$, MacDonald $\mathrm{M}$, et al. A randomised controlled trial of methadone maintenance treatment versus wait list control in an Australian prison system. Drug Alcohol Depend 2003;72:59-65.

25. Marzo JN, Rotily M, Meroueh F, et al. Maintenance therapy and 3-year outcome of opioid-dependent prisoners: a prospective study in France (2003-06). Addiction 2009;104:1233-40.

26. McMillan GP, Lapham S, Lackey M. The effect of a jail methadone maintenance therapy (MMT) program on inmate recidivism. Addiction 2008;103:2017-23.

27. Larney S. Does opioid substitution treatment in prison reduce injecting-related HIV risk behaviours? A systematic review. Addiction 2010;105:216-23.
28. Johnson SL, van de Ven JTC, Grant BA. Institutional methadone maintenance treatment: impact on release outcome and institutional behaviour. Ottawa: Addictions Research Centre, Correctional Service Canada, 2001.

29. Kinlock TW, Gordon MS, Schwartz RP, et al. A randomized clinical trial of methadone maintenance for prisoners: results at one-month post-release. Drug Alcohol Depend 2007;91:220-7.

30. Larney S, Toson B, Burns L, et al. Effect of prison-based opioid substitution treatment and post-release retention in treatment on risk of re-incarceration. Addiction 2012;107:372-80.

31. Degenhardt L, Larney S, Kimber J, et al. The impact of opioid substitution therapy on mortality post-release from prison. Addiction 2014. In press.

32. McKenzie M, Nunn A, Zaller N, et al. Overcoming obstacles to implementing methadone maintenance therapy for prisoners: implications for policy and practice. J Opioid Manag 2009;5:219-27. 